\title{
SURGICAL TREATMENT OF PERIODONTAL INTRABONY DEFECTS WITH CALCIUM SULPHATE IN COMBINATION WITH BETA-TRICALCIUM PHOSPHATE: CLINICAL OBSERVATIONS TWO YEARS POST-SURGERY
}

\author{
Sujith Sukumar ${ }^{1}$, Ivo Drízhal ${ }^{1}$, Vladimíra Paulusová ${ }^{1}$, Josef Bukač ${ }^{2}$
}

Charles University in Prague, Faculty of Medicine and University Hospital Hradec Králové, Czech Republic: Department of Dentistry ${ }^{1}$, Department of Medical Biophysics ${ }^{2}$

Summary: The study was designed to evaluate the clinical outcome of a composite material, beta-tricalcium phosphate in combination with calcium sulphate, in the treatment of periodontal intrabony defects. The combination of these materials is believed to aid in guided tissue regeneration owing to their properties. A total of 47 teeth with intrabony defects in 26 periodontitis patients were treated with Fortoss ${ }^{\circledR}$ Vital (Biocomposites, Staffordshire, UK). Clinical parameters were evaluated which included changes in probing depth, clinical attachment level/loss and gingival recession at the baseline and 2 years postoperatively. The mean differences in measurements between the baseline and 2 years postoperatively were a reduction of $2.07 \pm 1.14 \mathrm{~mm}(\mathrm{p}=0.000)$ in case of probing depth and a gain of $1.93 \pm 1.36 \mathrm{~mm}(\mathrm{p}=0.000)$ in clinical attachment level; but an increase of $0.14 \pm 0.73 \mathrm{~mm}(\mathrm{p}=0.571)$ in gingival recession. The study results show that the treatment with a combination of beta tricalcium phosphate and calcium sulphate led to a significantly favorable clinical improvement in periodontal intrabony defects 2 years after the surgery.

Key words: Beta tricalcium phosphate; Calcium sulphate; Periodontal regeneration; Intrabony defect; Bone graft

\section{Introduction}

Many different surgical techniques and materials have been reported in the literature to successfully treat periodontal intrabony defects. An ideal technique should be easier to perform, cost effective and should allow achieving periodontal regeneration. Various procedures have been advocated for regeneration of periodontal apparatus, such as open flap debridement (OFD) $(14,16,24,42)$, natural or synthetic filling materials $(5,39,41,43,45,46,55)$ and guided tissue regeneration (GTR) $(3,9,10,11,29,31)$. Generally, GTR was shown to be superior to OFD in that, it is able to produce better clinical results $(10,30,32,34)$.

GTR describes the procedures designed to manipulate the cells that repopulate the wound healing site so as to ensure that this repopulation includes cells that lead to regeneration of lost periodontal tissues. GTR aims to isolate the periradicular bone wound from the rest of the tissues using a barrier. This will allow the cells from the periodontal ligament to repopulate the blood coagulum that forms between the alveolar bone and root surface. The isolation of the wound is achieved using a physical barrier like a membrane $(9,13,15,26,32,34)$. There are different types of barrier membranes, both resorbable and non-resorbable. A better clinical outcome is anticipated when bone grafts are used in combination with GTR. This led to the widespread use of the combination technique. Different graft materials were used with different types of membranes in an attempt to achieve the best possible results.

Interest in bone replacement grafts has emerged from the desire to fill an intrabony or furcation defect rather than radically resect surrounding intact bone tissue. It is assumed that the application of bone grafts would potentially manipulate the biological response into a regenerative rather than a predominantly reparative pattern of periodontal healing $(17,18)$. Bone replacement grafts can be broadly classified into human bone and bone substitutes. This can be further classified into autografts, allografts, xenografts, and alloplasts $(33,52)$.

Alloplasts are synthetic, inorganic, biocompatible bone substitutes, which act primarily as defect fillers. Alloplasts can aid in bone regeneration by a process called osteoconduction. Beta tricalcium phosphate is one of the earliest calcium compounds to be used as a bone graft substitute. Structurally porous beta-tricalcium phosphate has a compressive strength and tensile strength similar to that of cancellous bone. It undergoes resorption over a 6-18 month period. Unfortunately, the replacement of beta-tricalcium phosphate by bone does not occur in a predictable way. That is, there is always less bone volume produced than the volume of the graft material used. For this reason, beta-tri- 
calcium phosphate has been used rather as an adjunctive with other less resorbable bone graft substitutes or as an expander for autogenous bone graft $(25,52)$.

Another calcium compound used as defect filler is calcium sulphate. Calcium sulphate, used by Dreesman in 1892 , is one of the earliest bone substitutes to be used to fill defects in the bone (37). It has a compressive strength greater than that of cancellous bone. It can act as a bioabsorbable barrier that prevents epithelial down growth during periodontal wound healing $(28,47,48,49,50)$, which makes it ideal for using as an adjunct with other graft materials in GTR (36). The goal of the current study was a 2-year retrospective evaluation of the clinical outcome of a composite material, beta-tricalcium phosphate in combination with calcium sulphate, in the treatment of human periodontal intra-bony defects.

\section{Methods}

\section{Patient population}

A total of 26 patients from the Department of Dentistry, Faculty of Medicine in Hradec Králové, Czech Republic, were enrolled in the study. Patients, in good general health, presented advanced periodontitis with deep intrabony defects treated using the composite material (Fortoss $^{\circledR}$ Vital). Patients were aged 21 to 58 years with a mean age of $42.27 \pm 10.66$ at the time of surgery. There were 9 males and 17 females, out of which 8 were smokers. Smokers were medium smokers, smoking up to 5 cigarettes a day.

Subject inclusion was based on the presence of at least one tooth with a probing depth (PD) of $\geq 5 \mathrm{~mm}$ and radiographic evidence of intrabony defect after initial periodontal therapy. The exclusion criteria consisted of patients with systemic diseases or medically compromised conditions and taking any drug known to interfere with the wound healing during the previous 6 months, pregnant and/or lactating women and insufficient dental hygiene characterized by a papilla bleeding index $(\mathrm{PBI})$ total score of $>15$. Teeth had to be vital or properly treated with root canal therapy. Signed consent form before surgery was obtained.

\section{Study design and clinical procedures}

All patients underwent initial therapy, consisting of oral hygiene instruction, full-mouth scaling and root planing, elimination of local plaque-retaining factors and restorations and occlusal adjustments when indicated. A total of 47 teeth with periodontal intrabony defects were included in this study. These defects were either 2 or 3 walled defects with 33 of those located around the anterior teeth and 7 each around the premolars and molars. All the defects were treated by the same clinician using standard clinical procedures. Clinical parameters like probing depth (PD), gingival recession (GR), clinical attachment level/loss (CAL), presence/absence of dental plaque and bleeding on probing (BOP) were recorded just before the surgery (baseline) and at 2 years postoperatively. Radiographs were also made be- fore the surgery and at 2 years postoperatively. The clinical parameters at the baseline and at 2 years postoperatively were compared and evaluated statistically to procure the study outcome. Radiographs were also compared to support the clinical outcome.

The surgical treatment phase was initiated only if the subject had a papilla bleeding index (PBI) total score of $\leq 15$. Under local anesthesia, a full-thickness mucoperiosteal flap was elevated using a crevicular incision on the facial and lingual surfaces of each tooth, segment or area involved. In the upper anterior regions papilla preservation incisions were made in the interdental area. Vertical release incisions were used when indicated. After flap elevation, a thorough root surface debridement was done using Gracey or universal curettes (Hu-Friedy, Chicago, IL, USA). All granulomatous tissues were removed from the osseous defects and defects were rinsed with saline (Fig. 1). Root surface conditioning was done using $2.5 \%$ tetracycline hydrochloride for 2-3 minutes followed by flushing with saline. Fortoss ${ }^{\circledR}$ Vital powder was mixed with the fluid supplied along with it in to a gritty mouldable paste and applied it in layers using a sterile instrument. The graft material was firmly pressed into the site using finger pressure over sterile gauze (Fig. 2). The defects were over-packed to allow for any settling of the mixture. Any excessive blood was removed from the site by using damp sterile gauze. Then the gauze was held on the graft for a few seconds. The mucoperiosteal flaps were approximated and sutured using resorbable sutures (Safil ${ }^{\circledR}$, Braun, Tuttlingen, Germany) (Fig. 3).

The patients were given post-operative instructions including rinsing with Listerine ${ }^{\circledR}$ (Johnson \& Johnson, Maidenhead, UK) mouth rinse for 2 weeks. Antibiotics (Amoxicillin $250 \mathrm{mg}$ with clavulanic acid $125 \mathrm{mg}$ or clarithromycin $250 \mathrm{mg}$ ) were prescribed to the patients for 7-14 days. The sutures were removed after 2 weeks and the surgical sites were cleansed gently with $3 \%$ hydrogen peroxide using a cotton swab. The patients were scheduled for recall visits at 3,6 and 12 months postoperatively. Oral hygiene was evaluated and supragingival prophylaxis was carried out at each recall visit.

\section{Clinical measurements}

The clinical measurements were performed randomly by 2 examiners, the surgeon being one of them. Both examiners recorded similar measurements during a 2 year trial period of cross-checking. Clinical parameters were recorded just before the surgery (baseline) and at 2 years postoperatively. These included probing depth (PD), gingival recession (GR), clinical attachment level/loss (CAL), bleeding on probing (BOP) at the vestibular, oral, mesial and distal surfaces of all teeth involved, presence/absence of dental plaque on the mesial and distal tooth surfaces, and mobility. The measurements were done using a calibrated periodontal probe (Williams color coded, Hu-Friedy, Chicago, IL, USA) at the surfaces on involved teeth and the highest value for each surface is reported. 


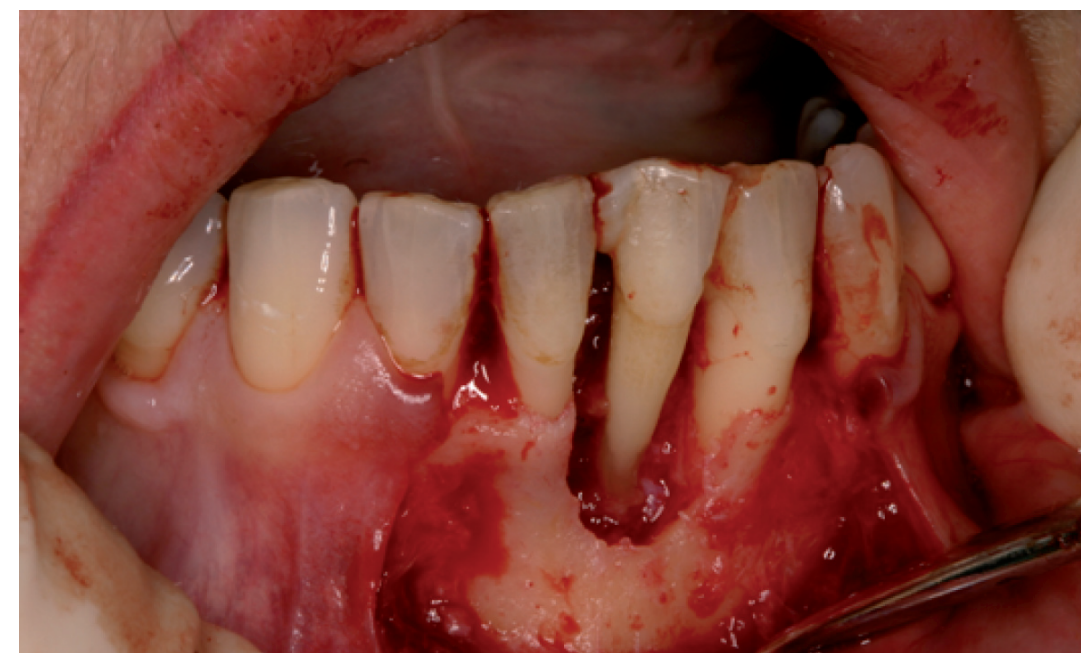

Fig. 1: Periodontal intrabony defect related to the lower left central incisor in a patient.

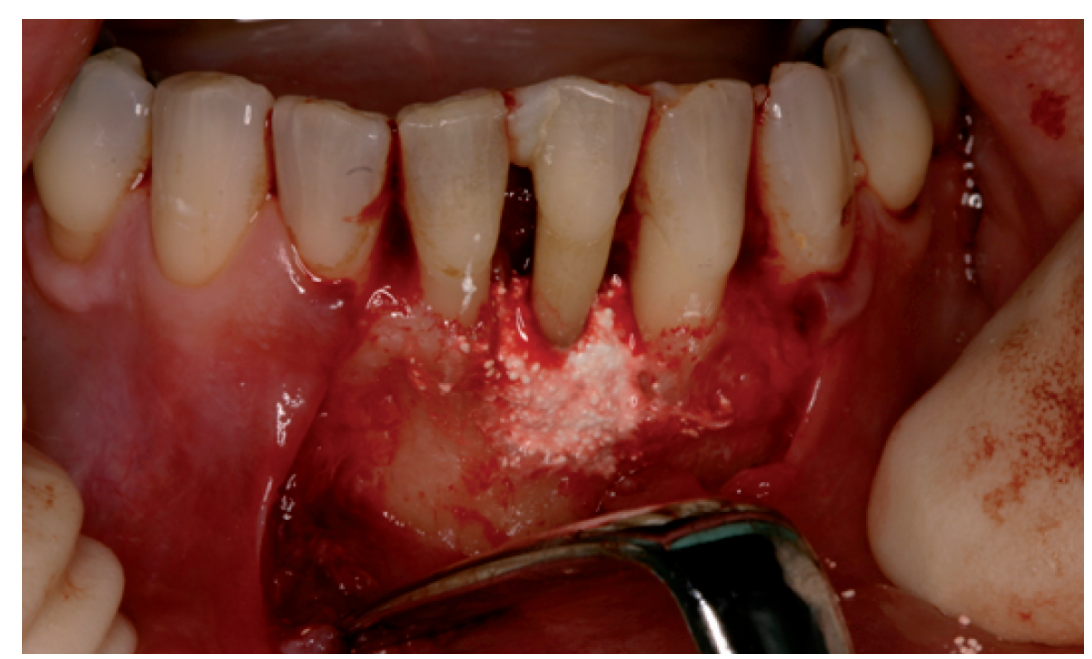

Fig. 2: Graft material applied in to the bony defect.

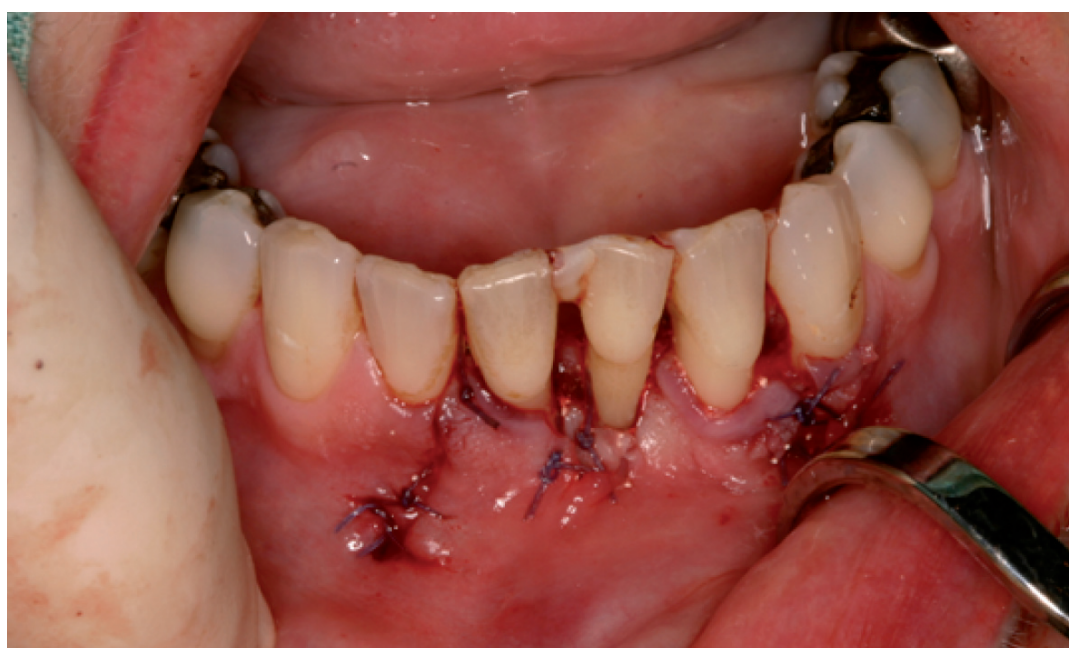

Fig 3: Sutures placed. 


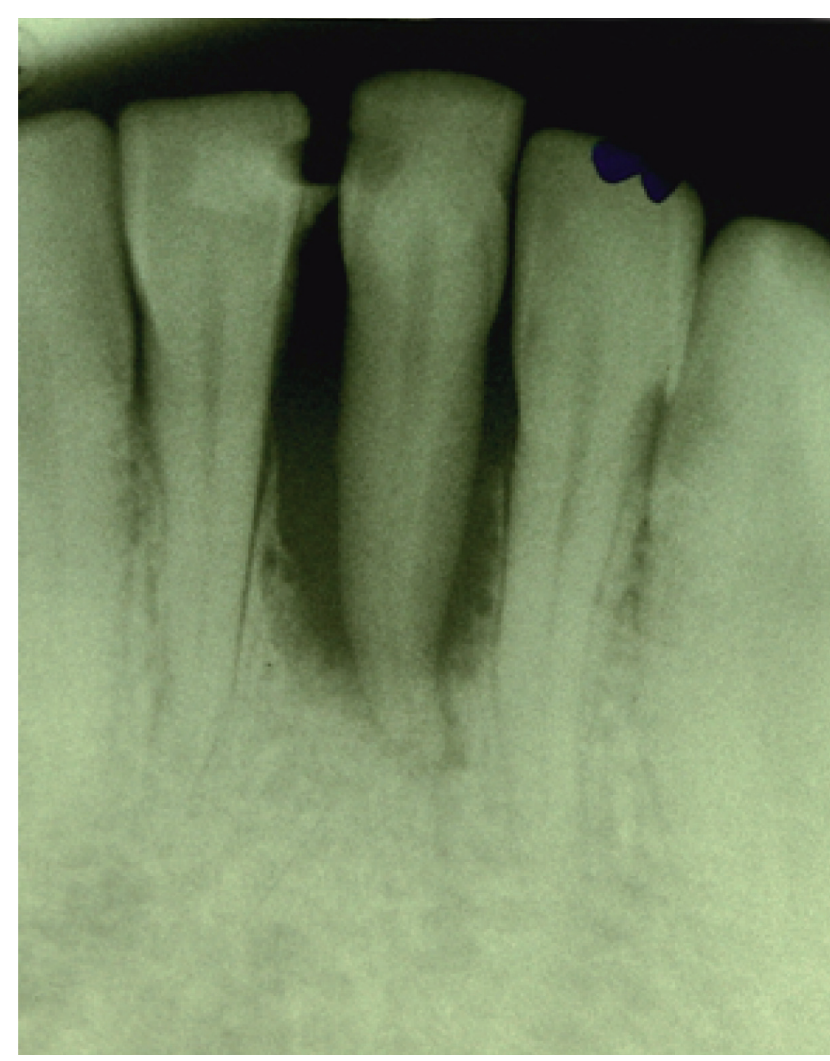

Fig 4: At the baseline.

\section{Radiographs}

Intraoral periapical radiographs were taken at the baseline and at 2 years postoperatively (Fig 4, 5). The radiographs were used only for the detection of bone fill in the defects and not for the measurements as the method employed were not standardized. Post-operative radiographs were compared to the ones at the baseline in order to evaluate the bone fill and also to compare that with the clinical measurements.

\section{Statistical analysis}

Comparisons between baseline and 2 year data were made using a paired t-test and Fisher's exact test. Mean differences in the PD, GR and CAL were calculated on individual surfaces and also on the whole tooth. All the surfaces of an involved tooth were taken into account irrespective of the presence/absence of $\mathrm{PD} \geq 5 \mathrm{~mm}$. This was done to assess the outcome of surgery on the non-involved sites of the involved tooth as well. Data were expressed as means \pm standard deviation. The level of significance was set at 0.05 .

\section{Results}

Clinically, the graft material used was easy to handle, packed well into defects, strongly adherent, hardened within a few minutes and seemingly biocompatible. Wound

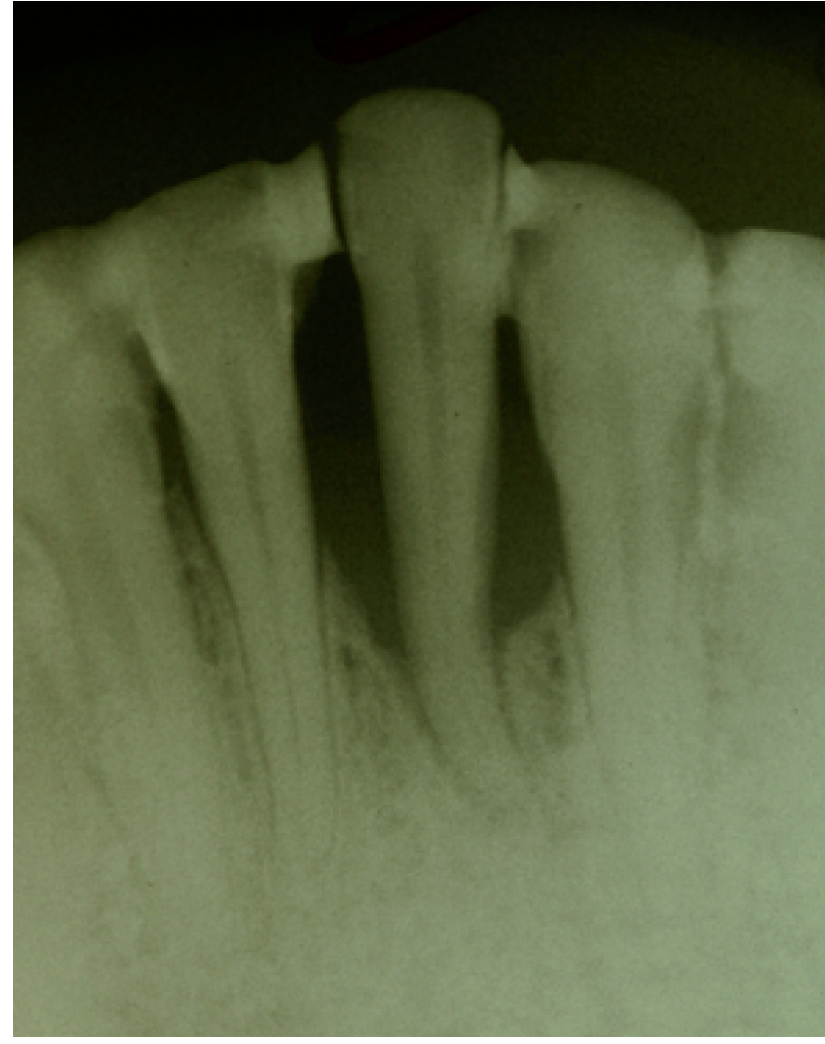

Fig. 5: 2 years postoperatively.

healing was uneventful. No patients reported a significant postoperative pain during the first week. 8 patients did not turn up for all scheduled recall visits. All of them reported at 2 years postoperatively.

A decrease in probing depths was noticed in 25 patients out of the total 26. The number of BOP positive sites was reduced from 67 at baseline to 28 at 2 years postoperatively. The number of sites with presence of plaque got decreased from 18 to 15 during the same interval.

Tables 1 and 2, show the differences in deep probing depth measurements at the baseline and at 2 years postoperatively. There were 83 PD measurements out of the total 188 measurements in relation to the 47 involved teeth, which were $\geq 5 \mathrm{~mm}$ at the baseline. A 2-year postoperative recall check showed a significant decrease in this number to 13 . There was a significant decrease in the numbers in relation to the frontal teeth and molars and also in the vestibular aspect of all teeth involved.

Tables 3 and 4, show the changes in CAL measurements during the same period. Total CAL measurements of $\geq 5 \mathrm{~mm}$ at the baseline was 105 which got reduced by almost half to 54 at 2 years postoperatively. Again, the numbers were much more significant in relation to the frontal teeth and in the proximal and oral aspects.

The mean differences in measurements between the baseline and two years postoperatively are a reduction of $2.07 \pm 1.14 \mathrm{~mm}(\mathrm{p}=0.000)$ in case of $\mathrm{PD}$, a gain of 1.93 
Tab. 1: PD measurements $\geq 5 \mathrm{~mm}$ at baseline.

\begin{tabular}{|l|c|c|c|c|}
\hline & V & M & O & D \\
\hline Frontal & 8 & 27 & 11 & 11 \\
\hline Premolar & 0 & 4 & 3 & 4 \\
\hline Molar & 1 & 6 & 3 & 5 \\
\hline Total & $\mathbf{9}$ & $\mathbf{3 7}$ & $\mathbf{1 7}$ & $\mathbf{2 0}$ \\
\hline
\end{tabular}

$\mathrm{V}=$ vestibular/buccal, $\mathrm{M}=$ mesial, $\mathrm{O}=$ oral $/$ lingual, $\mathrm{D}=$ distal

Tab. 2: PD measurements $\geq 5 \mathrm{~mm}$ at 2 years postoperatively.

\begin{tabular}{|l|c|c|c|c|}
\hline & V & M & O & D \\
\hline Frontal & 0 & 4 & 3 & 4 \\
\hline Premolar & 0 & 2 & 0 & 0 \\
\hline Molar & 0 & 0 & 0 & 0 \\
\hline Total & $\mathbf{0}$ & $\mathbf{6}$ & $\mathbf{3}$ & $\mathbf{4}$ \\
\hline
\end{tabular}

Tab. 3: CAL measurements $\geq 5 \mathrm{~mm}$ at baseline.

\begin{tabular}{|l|c|c|c|c|}
\hline & V & M & O & D \\
\hline Frontal & 9 & 27 & 20 & 16 \\
\hline Premolar & 0 & 4 & 3 & 6 \\
\hline Molar & 4 & 7 & 4 & 5 \\
\hline Total & $\mathbf{1 3}$ & $\mathbf{3 8}$ & $\mathbf{2 7}$ & $\mathbf{2 7}$ \\
\hline
\end{tabular}

Tab. 4: CAL measurements $\geq 5 \mathrm{~mm}$ at 2 years postoperatively.

\begin{tabular}{|l|c|c|c|c|}
\hline & V & M & O & D \\
\hline Frontal & 7 & 17 & 8 & 10 \\
\hline Premolar & 0 & 0 & 1 & 1 \\
\hline Molar & 3 & 4 & 1 & 2 \\
\hline Total & $\mathbf{1 0}$ & $\mathbf{2 1}$ & $\mathbf{1 0}$ & $\mathbf{1 3}$ \\
\hline
\end{tabular}

$\pm 1.36 \mathrm{~mm}(\mathrm{p}=0.000)$ in CAL and an increase of 0.14 $\pm 0.73 \mathrm{~mm}(\mathrm{p}=0.571)$ in GR. These are illustrated in tables 5, 6 and 7. Table 5 shows that the mean increase in GR was much lower in the mesial and distal aspects of teeth. Also, the maximum increase in GR at 2 years postoperatively is $3 \mathrm{~mm}$ and the maximum decrease achieved is also $3 \mathrm{~mm}$.

In table 6 the changes in PD are shown. There was a significant mean reduction in the proximal aspects of the teeth with $9 \mathrm{~mm}$ being the maximum reduction in PD and $2 \mathrm{~mm}$ the maximum increase. Table 7 shows the mean gain of CAL, which was much higher in the mesial and distal aspects.

There were no significant differences between smokers and non-smokers $(p=1.000)$ and presence or absence of plaque and BOP. But in one patient where an increase in PD and CAL was noticed 2 years after the surgery, a combination of different negative factors like smoking, inappropriate oral hygiene and non-compliance with the follow-up schedule during the maintenance phase were present simultaneously.

Intraoral periapical radiographs showed bone fill in the defects in patients where PD got reduced after the surgical treatment (Fig. 4, 5).

\section{Discussion}

Bone grafting is now a well-recognized choice in the treatment of periodontal osseous defects, especially when used along with barrier membranes. Various types of bone grafts and also their combinations are used with varying degrees of success. Autografts have been considered to be the gold standard among bone replacement grafts as they can induce osteogenesis $(22,33)$. However, there are some li-

Tab. 5: Mean differences in gingival recession (GR) measurements before and 2 years postoperatively.

\begin{tabular}{|c|c|c|c|c|}
\hline \multicolumn{5}{|c|}{ GR (Increase= "+", decrease=“ -“) } \\
\hline V & M & O & D & Average \\
\hline$+0.40(-2$ to 3$)$ & $-0.06(-2$ to 3$)$ & $+0.27(-2$ to 3$)$ & $-0.04(-3$ to 2$)$ & $\mathbf{+ 0 . 1 4}$ \\
\pm 1.17 & \pm 1.11 & \pm 0.94 & \pm 1.33 & $\pm \mathbf{0 . 7 3}$ \\
\hline
\end{tabular}

- values in millimeters; ** maximum and minimum values in brackets

Tab. 6: Mean differences in periodontal probing depth (PD) measurements before and 2 years postoperatively.

\begin{tabular}{|c|c|c|c|c|}
\hline \multicolumn{5}{|c|}{ PD (Increase= "+", decrease=" -") } \\
\hline $\mathrm{V}$ & $\mathrm{M}$ & $\mathrm{O}$ & $\mathrm{D}$ & Average \\
\hline$-0.96(-6$ to 1$)$ & $-3.49(-8$ to 2$)$ & $-1.74(-6$ to 2$)$ & $-2.11(-9$ to 1$)$ & $\mathbf{- 2 . 0 7}$ \\
\pm 1.18 & \pm 2.47 & \pm 2.16 & \pm 2.15 & $\pm \mathbf{1 . 1 4}$ \\
\hline
\end{tabular}

Tab. 7: Mean difference in clinical attachment level (CAL) measurements before and 2 years postoperatively.

\begin{tabular}{|c|c|c|c|c|}
\hline \multicolumn{5}{|c|}{ CAL (Gain= “+”, Loss= “.”) } \\
\hline $\mathrm{V}$ & $\mathrm{M}$ & $\mathrm{O}$ & $\mathrm{D}$ & Average \\
\hline$+0.55(-3$ to 6$)$ & $+3.55(-2$ to 9$)$ & $+1.48(-3$ to 6$)$ & $+2.13(-3$ to 8$)$ & $\mathbf{+ 1 . 9 3}$ \\
\pm 1.95 & \pm 2.60 & \pm 2.36 & \pm 2.54 & $\pm \mathbf{1 . 3 6}$ \\
\hline
\end{tabular}


mitations for the autografts like a surgical donor site is needed and availability of graft bone is limited. The alloplastic grafts or synthetic bone graft substitutes as yet offer only a part solution to the management of localized bone loss. They possess some of the desired mechanical qualities of bone as well as osteoconductive properties but are largely reliant on viable periosteum/bone for their success. They primarily serve as defect filler. In the present study, we have evaluated the effectiveness of a novel composite alloplast in the treatment of periodontal intrabony defects.

The use of a composite graft containing beta-tricalcium phosphate and calcium sulphate was described in only a few reports and studies $(38,51,53,54)$. In those reports and studies it was found that the use of this particular graft provided good results. In a clinical study published in 2009 by Stein et al, it was found that the clinical benefits of a biphasic composite graft containing beta-tricalcium phosphate and calcium sulphate were equivalent to that of autogenous bone spongiosa and superior to that of OFD alone. At 12 months postoperatively, the patients treated with the composite graft exhibited a mean PD reduction of $3.6 \pm 0.7 \mathrm{~mm}$ and a mean CAL gain of $3.0 \pm 0.8 \mathrm{~mm}$ (51) The study done on the iliac crest of dogs by Podaropoulos et al. in 2009 revealed that the mean percentage of new bone regeneration after 4 months by histological evaluation and morphometric analysis was $49.38 \%$ (38). Structurally porous beta-tricalcium phosphate has a compressive strength and tensile strength similar to that of cancellous bone. It undergoes resorption over a 6-18 month period. Calcium sulphate has a compressive strength greater than that of cancellous bone. It can act as a barrier membrane as well, which makes it ideal for using as an adjunct with other graft materials. It requires only 5-7 weeks for complete resorption $(4,52)$.

Fortoss ${ }^{\circledR}$ Vital which is a combination of beta-tricalcium phosphate and calcium sulphate is being used in the treatment of periodontal intrabony defects in our department since the year 2003. The main reasons for choosing this bone graft material over the conventional membrane and graft technique are many-fold: it is easy to use, it offers the possibility to treat periodontal intrabony defects spanning more than 2 teeth, the use of a membrane is not required, the surgical time is reduced and thus more economical.

Results from present investigation showed that the graft material used was effective in significantly improving the clinical parameters at 2 years after surgery. The overall reduction in PD and gain of attachment were found to be highly statistically significant and the mean difference in GR between the baseline and at 2 years postoperatively was negligible and not significant statistically. Ideally, a comparative study with open flap debridement and/or using a different bone graft material in treating comparable defect pairs would have been more significant to highlight the outcome of treatment using Fortoss ${ }^{\circledR}$ Vital. The amount of PD reduction was found to be greater in the deeper defects. In some cases, this reduction was up to $9 \mathrm{~mm}$. PD reduction was achieved in 25 of the total 26 patients; there was an increase of PD in one patient 2 years postoperatively. The local factors and the non-compliance of the patient probably would have resulted in the undesired result. After 2 years, the number of sites with bleeding on probing was reduced to almost half. The number of proximal sites (mesial and distal) with plaque deposits was also reduced.

Several studies were done to evaluate the effectiveness of calcium sulphate and of beta-tricalcium phosphate in combination with other materials resulting in good clinical outcomes. A study by Harris in 2004 evaluating a composite bone graft (demineralized freeze-dried bone allograft, calcium sulphate, tetracycline and porous hydroxyapatite) and calcium sulphate barrier showed a mean decrease of $4.7 \mathrm{~mm}$ of PD, mean gain of $3.7 \mathrm{~mm}$ of CAL and a mean increase of $1.0 \mathrm{~mm}$ of GR at 4-6 months postoperatively (23). In another study by Paolantonio et al. using calcium sulphate barrier implant and barrier revealed a mean decrease of $4.4 \mathrm{~mm}$ of PD, mean gain of $2.7 \mathrm{~mm}$ of CAL and a mean increase of $1.6 \mathrm{~mm}$ of GR at 12 months postoperatively (35). In a study published in 2008 by Döri F, at 1 year after therapy, the sites treated with platelet rich plasma+ beta-tricalcium phosphate+ GTR showed a reduction in mean PD from $9.1 \pm 0.6 \mathrm{~mm}$ to $3.3 \pm 0.5 \mathrm{~mm}(\mathrm{P}<0.001)$ and a change in mean CAL from $10.1 \pm 1.3 \mathrm{~mm}$ to $5.7 \pm 1.1 \mathrm{~mm}$ (12). Most of these studies used clinical measurements along with standardized radiographs for comparison. Unlike the present study, all these studies were short-term studies and have considered only the affected area around the tooth, where the pocket depths were deeper, which may influence the results.

Measurement methods for the assessment of clinical outcome variables, such as probing depths, attachment level and gingival recession, have varied between studies, particularly with regard to the use of automatic or pressure sensitive or conventional probes and the use of a stent as a reference point (40). The key element is the consistency of the assessment throughout the study. In the present study, an occlusal stent was not fabricated; the cement enamel junction and the free gingival margin served as the reference point. Manual probes were used to measure the variables. The ability of a probe to penetrate into a periodontal pocket is related to several factors like the probing force, diameter of the probe and the gingival tissue tone $(1,27$, 44). In our study, Williams color-coded probe (Hu-Friedy, Chicago, IL, USA) was used throughout in order to ensure the consistency in probe diameter. The clinical measurements were performed randomly by 2 examiners at the desired intervals before and after the surgery. The surgeon who performed the surgical part was one of the examiners. Both the examiners recorded similar measurements during a 2 year trial period of cross-checking which ensured the similarity in probing force and method. Gingival tissue consistency may be modified after the placement of graft material in to the defect, which in turn can impede penetration of the periodontal probe causing false positive results (6). 
Unlike usual studies, we have considered the unaffected sides of the tooth as well. We have done this as the surgical wound included all the sides of the tooth. Although standardized radiographs were not made in this study, 2 years after treatment radiographic defect fill with bone-like radio opaque tissue, which was indistinguishable from native bone and therefore considered as new bone, was observed. The shortcomings of the study could be a small patient group, no radiographic analysis or surgical re-entry to establish the bone fill/regeneration and the non-usage of stents during clinical measurements and also the non-involvement of a control group where another surgical technique or material was used.

Conventional therapy is capable of controlling periodontal disease. Scaling and root planning allow reduction in pocket depth mainly by new connective tissue/epithelial attachment; with a probable gain in clinical attachment level. Periodontal literature is sated with studies showing the treatment of periodontitis by scaling and root planing results in reductions of probing depths $(2,8,19,20)$. The decrease in probing depth is caused partly by the shrinkage of the pocket soft tissue wall manifested as recession of the gingival margin which results from a decrease in soft tissue inflammation; and partly from the gain in clinical attachment $(2,8,19,20)$. In a thorough evidence-based review, Cobb calculated the mean probing depth reduction and gain of clinical attachment that can be achieved with root planing at sites that initially were 4 to $6 \mathrm{~mm}$ in depth and 7 $\mathrm{mm}$ or greater in depth. He reported mean pocket depth reductions of $1.29 \mathrm{~mm}$ and $2.16 \mathrm{~mm}$, respectively, and mean gains of clinical attachment of $0.55 \mathrm{~mm}$ and $1.29 \mathrm{~mm}$, respectively (8).

The regenerative procedures are performed after the conventional scaling and root planing to attain further improvement of the tissues destroyed by periodontitis. These procedures can promote further bone fill, thus improving the supporting structures thereby improving the long-term prognosis of the tooth.

\section{Conclusion}

The treatment with a synthetic bone graft containing a combination of beta-tricalcium phosphate and calcium sulphate led to a significantly favorable clinical improvement in periodontal intrabony defects 2 years after the surgery. A much longer term evaluation and further studies are necessary to completely ascertain the effectiveness of this material, and a larger sample size is also recommended.

\section{Acknowledgement}

This paper was supported by the research grant FN HK MZO 00179906.

\section{References}

1. Armitage GC, Svanberg GK, Loe H. Microscopic evaluation of clinical measurements of connective tissue attachment levels. J Clin Periodontol 1977; 4: $173-190$.
2. Badersten A, Nilveus R, Egelberg J. Effect of nonsurgical periodontal therapy. I: moderately advanced periodontitis. J Clin Periodontol. 1981; 8: 57-72.

3. Becker W, Becker BE. Treatment of mandibular 3-wall intrabony defects by flap debridement and expanded polytetrafluoroethylene barrier membranes. Long-term valuation of 32 treated patients. J Periodontol 1993; 64(11 Suppl): 1138-1144.

4. Bell WH. Resorption rates of bone and bone substitutes. Oral Surg. 1964; 17: 650-7.

5. Bowen JA, Mellonig JT, Gray JL, Towle HT. Comparison of decalcified freezedried bone allograft and porous particulate hydroxyapatite in human periodontal osseous defects. J Periodontol. 1989; 60(12): 647-654.

6. Camargo PM, Lekovic V, Weinlaender M, et al. A controlled re-entry study on the effectiveness of bovine porous bone mineral used in combination with a collagen membrane of porcine origin in the treatment of intrabony defects in humans. J Clin Periodontol 2000; 27: 889-896.

7. Caton J, Nyman S, Zander H. Histometric evaluation of periodontal surgery: II Connective tissue attachment levels after four regenerative procedures. J Clin Periodontol 1980; 7: 224-231.

8. Cobb CM. Non-surgical pocket therapy: Mechanical. Ann Periodontol. 1996; 1: 443-490.

9. Cortellini P, Pini Prato G, Tonetti MS. Periodontal regeneration of human intrabony defects. I. Clinical measures. J Periodontol 1993; 64: 254-260.

10. Cortellini P, Labriola A, Tonetti MS. Regenerative periodontal therapy in intrabony defects: state of the art. Minerva Stomatol 2007; 56(10): 519-539.

11. Cortellini P, Pini Prato G, Tonetti MS. Periodontal regeneration of human intrabony defects with bioresorbable membranes. A controlled clinical trial. J Periodontol 1996; 67(3): 217-223

12. Döri F, Huszár T, Nikolidakis D, et al. Effect of Platelet-Rich Plasma on the Healing of Intrabony Defects Treated With Beta Tricalcium Phosphate and Expanded Polytetrafluoroethylene Membranes. J Periodontol 2008; 79(4): 660-669.

13. Dřizhal I, Červinka M, Taha M, Strnad L. Řizená tkáňová regenerace - uplatnění v parodontologii. Quintessenz - Parodontologie 2001; 2(11): 18-25.

14. Durwin A, Chamberlain H, Garrett S, Renvert S, Egelberg J. Healing after treatment of periodontal intraosseous defects. IV. Effect of a non-resective versus partially respective approach. J Clin Periodontol 1985; 12: 525-539.

15. Fassmann A. Ŕízená tkáňová a kostní regenerace ve stomatologii. Praha: Grada Publishing, 2002: 13-14

16. Froum SJ, Coran M, Thaller B, Kushner L, Scopp IW, Stahl SS. Periodonta healing following open debridement flap procedures. I. Clinical assessments of soft tissue and osseous repair. J Periodontol 1982; 53: 8-14.

17. Garrett S, Bogle G. Periodontal regeneration with bone grafts. Curr Opin Periodontol 1994: 168-177.

18. Garrett S. Periodontal regeneration around natural teeth. Ann Periodontol (World Workshop in Periodontics) 1996; 1:621-666

19. Greenstein G. Nonsurgical periodontal therapy in 2000: a literature review. J Am Dent Assoc. 2000; 131: 1580-1592.

20. Greenstein G. Periodontal response to mechanical nonsurgical therapy: a review. J Periodontol. 1992; 63: 118-130.

21. Haghighati F, Saaveh G. Essentials in periodontal regeneration. JDT 2007; 4: 78-86.

22. Hanes PJ. Bone replacement grafts for the treatment of periodontal intrabony defects. Oral Maxillofac Surg Clin North Am 2007; 19(4): 499-512.

23. Harris RJ. Clinical evaluation of a composite bone graft with a calcium sulfate barrier. J Periodontol 2004; 75(50): 685-692.

24. Heitz-Mayfield LJ, Trombelli L, Heitz F, Needleman I, Moles D. A systematic review of the effect of surgical debridement vs. non-surgical debridement for the treatment of chronic periodontitis. J Clin Periodontol 2002; 29(3): 92-102.

25. Holinger JO, Brekke J. Role of bone substitutes, Clin Orthoped 1996; 324: 55-65.

26. Jepsen S, Eberhard J, Herrera D, Needleman I. A systematic review of guided tissue regeneration for periodontal furcation defects. What is the effect of guided tissue regeneration compared with surgical debridement in the treatment of furcation defects? J Clin Periodontol 2002; 29(3): 103-116.

27. Keagle JG, Garnick JJ, Searle JR, King GE, Morse PK. Gingival resistance to probing forces. I. Determination of optimal probe diameter. J Periodontol 1989; 60: $167-171$.

28. Kim CK, Kim HY, Chai JK, et al. Effect of a calcium sulfate implant with calcium sulfate barrier on periodontal healing in 3-wall intrabony defects in dogs. J Periodontol 1998 ; 69(9): 982-988.

29. Laurell L, Falk H, Fornell J, Johard G, Gottlow J. Clinical use of a bioresorbable matrix barrier in guided tissue regeneration therapy. Case series. J Periodontol 1994; 65(10): 967-975.

30. Laurell L, Gottlow J, Zybutz M, Persson R. Treatment of intrabony defects by different surgical procedures. A literature review. J Periodontol 1998; 69(3): 303-313.

31. Mattson JS, McLey LL, Jabro MH. Treatment of intrabony defects with collagen membrane barriers. Case reports. J Periodontol 1995; 66(7): 635-645.

32. Murphy KG, Gunsolley JC. Guided tissue regeneration for the treatment of periodontal intrabony and furcation defects. A systematic review. Ann Periodontol 2003; 8(1): 266-302.

33. Nasr HF, Aichelmann-Reidy ME, Yukna RA. Bone and bone substitutes. Periodontology 2000 1999; 19: 74-86. 
34. Needleman I, Worthington HV, Giedrys-Leeper E, Tucker R. Guided tissue regeneration for periodontal infra-bony defects. Cochrane Database of Systematic Reviews 2006; 2: Art. No.: CD001724.

35. Paolantonio M, et al. Surgical treatment of periodontal intrabony defects with calcium sulfate implant and barrier versus collagen barrier or open flap debridement alone: A 12-month randomized controlled clinical trial. J Periodontol 2008; 79(10): 1886-1893.

36. Pecora G, Andreana S, Margarone J, Covani U, Sottosanti J. Bone regeneration with a calcium sulfate barrier. Oral Surg Oral Med Oral Path Oral Radio Endo 1997; 84: 424-429.

37. Peltier LF. The use of plaster of Paris to fill defects in bone. Clin Ortop 1961; 21 $1-31$

38. Podaropoulos L, Veis AA, Papadimitriou S, Alexandridis C, Kalyvas D. Bone regeneration using beta-tricalcium phosphate in a calcium sulfate matrix. J Oral Implantol 2009; 35(1): 28-36.

39. Quintero G, Mellonig J, Gambili V, Pelleu B. A six-month clinical evaluation of decalcified freeze dried bone allograft in periodontal osseous defects. $\mathrm{J} \mathrm{Pe}$ riodontol 1982; 53: 726-730.

40. Reddy MS, Jeffcoat MK. Methods of assessing periodontal regeneration. Periodontol 2000 1999; 19: 87-103.

41. Renvert S, Garrett S, Schallhorn R, Egelberg J. Healing after treatment of periodontal intraosseous defects. III. Effect of osseous grafting and citric acid conditioning. J Clin Periodontol 1985; 12: 441-455.

42. Renvert S, Nilveus R, Egelberg J. Healing after treatment of periodontal intraosseous defects. V. Effect of root planning versus flap surgery. J Clin Periodonto 1985; 12: 619-629.

43. Reynolds MA, Aichelmann-Reidy ME, Branch-Mays GL, Gunsolley JC. The efficacy of bone replacement grafts in the treatment of periodontal osseous defects. A systematic review. Ann Periodontol 2003; 8: 227-265.
44. Robinson PJ, Vitek RM. The relationship between gingival inflammation and resistance to probe penetration. J Periodontol Res 1979; 14: 239-243.

45. Rosen PS, Reynolds MA, Bowers GM. The treatment of intrabony defects with bone grafts. Periodontology 2000 2000; 22: 88-103.

46. Rosenberg E, Rose LF. Biological and clinical considerations for autografts and allografts in periodontal regeneration therapy. Dent Clin North Am 1998; 42: 467-490.

47. Sottosand JS. Aesthetic extractions with calcium sulfate and the principles of guided tissue regeneration. Pract Periodontics Aesthet Dent 1993; 5: 61-69.

48. Sottosanti J. Calcium sulfate: a biodegradable and biocompatible barrier for guided tissue regeneration. Compend Contin Educ Dent 1992; 13: 226-34.

49. Sottosanti J. Calcium sulfate: an aid to periodontal, implant and restorative therapy. Calif Dent Assoc J 1992:20:45, 60, 62.

50. Sottosanti JS. Calcium sulfate: a valuable addition to the implant/bone regeneration complex. Dent Implantol Update 1997; 8: 25-29.

51. Stein JM, Fickl S, , Hoischen U, Ocklenburg C, Smeets R. Clinical evaluation of a biphasic calcium composite grafting material in the treatment of human periodontal intrabony defects: a 12-month randomized controlled clinical trial. J Periodontol 2009; 80(11): 1774-1782.

52. Sukumar S, Dřízhal I. Bone grafts in periodontal therapy. Acta Medica (Hradec Králové) 2008; 51(4): 203-207.

53. Tözüm TF, Erdal C, Saygun I. Treatment of Periapical Dental Implant Pathology with Guided Bone Regeneration - Case Report. Turk J Med Sci 2006; 36(3): 191-196.

54. Tözüm TF, Sencimen M, Ortakoglu K, Ozdemir A, Aydin Ö, Keles M. Diagnosi and treatment of a large periapical implant lesion associated with adjacent natural tooth: a case report. Oral Surg Oral Med Oral Pathol Oral Radiol Endod 2006 Jun; 101(6): e132-8.

55. Yukna RA. Osseous defect responses to hydroxylapatite grafting versus open flap debridement. J Clin Periodontol 1989; 16(7): 398-402.

Received: 06/04/2010

Accepted in revised form: 29/11/2010.

\section{Corresponding author:}

Dr. Sujith Sukumar, BDS, University Hospital, Department of Dentistry, Sokolská 581, 50005 Hradec Králové, Czech Republic; e-mail: docsujith@gmail.com 